\title{
Coupled Coincidence Fixed Point Theorems in S-Metric Spaces
}

\author{
Hans Raj ${ }^{1}$, Nawneet Hooda ${ }^{2}$ \\ ${ }^{I}$ (Department of Mathematics, DCRUST, Murthal, Sonepat, India) \\ ${ }_{2}^{2}$ (Department of Mathematics, DCRUST, Murthal, Sonepat, India)
}

Abstract: In this paper we prove some coupled fixed point theorems in S-metric spaces.

MSC: $47 \mathrm{H} 10,54 \mathrm{H} 25$

Keywords: Coupled coincidence point, coupled fixed pont, mixed g-monotone property, S-metric space

\section{Introduction}

Metric spaces have very wide applications in mathematics and applied sciences. Therefore, many authors have tried to introduce the generalizations of metric spaces in many ways. In 1989, Gahler [2-3], introduced the notion of 2-metric spaces and Dhage [1] introduced the notion of $D$-metric spaces. They proved some results related to 2-metric and $D$-metric spaces. After this Mustafa and Sims [4] proved that most of the results of Dhage's $D$-metric spaces are not valid. So, they introduced the new concept of generalized metric space called G-metric space. Now, recently Sedghi et al. [5] have introduced the notion of S-metric spaces as the generalization of G-metric and $D^{*}$-metric spaces. They proved some fixed point results in S-metric spaces. Some results have been obtained in [5-7] by Sedghi et al. In the present paper, we prove some coupled coincidence point results in S-metric space which are the generalizations of some fixed point theorems in metric spaces [8-12].

\section{Preliminaries}

Here we give some definitions which are throughout used in this paper.

Definition 2.1 ([5]). Let $X$ be a nonempty set. An S-metric on $X$ is a function $S: X^{3} \rightarrow[0, \infty)$ that satisfies the following conditions, for each $x, y, z, a \in X$.

(i) $\quad S(x, y, z) \geq 0$

(ii) $\quad S(x, y, z)=0$ if and only if $x=y=z$

(iii) $\quad S(x, y, z) \leq S(x, x, a)+S(y, y, a)+S(z, z, a)$

Then the pair $(X, S)$ is called an $S$-metric space.

Definition 2.2 ([14]). Let $(X, \leq)$ be a partially ordered set equipped with a metric $S$ such that $(X, S)$ is a metric space. Further, equip the product space $X \times X$ with the following partial ordering:

$$
\begin{aligned}
& \text { for }(x, y),(u, v) \in X \times X, \\
& \text { define }(u, v) \leq(x, y) \Leftrightarrow x \geq u, y \leq v .
\end{aligned}
$$

Definition 2.3 ([14]). Let $(X, \leq)$ be a partially ordered set and $F: X \times X \rightarrow X$. One says that $F$ enjoys the mixed monotone property if $(x, y)$ is monotonically nondecreasing in $x$ and monotonically nonincreasing in $y$; that is, for any $x, y \in X$,

$$
\begin{aligned}
& x^{1}, x^{2} \in X, x^{1} \leq x^{2} \Rightarrow F\left(x^{1}, y\right) \leq F\left(x^{2}, y\right), \\
& y^{1}, y^{2} \in X, y^{1} \leq y^{2} \Rightarrow F\left(x, y^{1}\right) \geq F\left(x, y^{2}\right),
\end{aligned}
$$

Definition 2.4 ([14]). An element $(x, y) \in X \times X$ is said to be a coupled fixed point of the mapping $F: X \times X \rightarrow X$ if

$$
F(x, y)=x \quad \text { and } \quad F(y, x)=y \text {. }
$$

Lemma 2.5 ([7]). In an $S$-metric space, we have $S(x, x, y)=S(y, y, x)$.

Definition 2.6 ([13]). Let $(X, \leq)$ be a partially ordered set and $F: X \times X \rightarrow X$ and $g: X \rightarrow X$ two mappings. The mapping $F$ is said to have the mixed $g$-monotone property if $F$ is monotone $g$ nondecreasing in its first argument and is monotone $g$-nonincreasing in its second argument, that is,

if, for all $x^{1}, x^{2} \in X, g\left(x^{1}\right) \leq g\left(x^{2}\right)$ implies $F\left(x^{1}, y\right) \leq F\left(x^{2}, y\right)$, for any $y \in X$, and, 
for all $y^{1}, y^{2} \in X, \quad g\left(y^{1}\right) \leq g\left(y^{2}\right)$ implies $F\left(x, y^{1}\right) \leq F\left(x, y^{2}\right)$, for any $x \in X$.

Definition 2.7 ([13]). An element $(x, y): X \rightarrow X$ is called a coupled coincidence point of mappings $F: X \rightarrow X$ and $g: X \rightarrow X$ if

$$
F(x, y)=g(x), F(y, x)=g(y) \text {. }
$$

Theorem 2.8 ([13]). Let $(X, \leq)$ be a partially ordered set equipped with a metric $d$ such that $(X, d)$ is a complete metric space. Assume that there is a function $:[0, \infty) \rightarrow[0, \infty)$ with $(t)<t$ and $\lim _{r \rightarrow t^{+}} \phi(r)<t$ for each $t>0$. Let $F: X \times X \rightarrow X$ and $g: X \rightarrow X$ be maps such that $\mathrm{F}$ has the mixed g-monotone property and

$$
d(F(x, y), F(u, v)) \leq \phi \frac{(d(g(x), g(u)+d(g(y), \mathrm{g}(v)))}{2}
$$

for all $x, y, u, v \in X$ for which $g(x) \leq g(u)$ and $g(y) \geq g(v)$.

Suppose that $F(X \times X) \subseteq g(X), g$ is continuous and commutes with $F$ besides

(a) $\quad F$ is continuous,

(b) $\quad X$ has the following properties:

(i) if a nondecreasing sequence $\left\{x_{n}\right\} \rightarrow x$, then $x_{n} \leq x$ for all $n$,

(ii) if a nonincreasing sequence $\left\{y_{n}\right\} \rightarrow y$, then $y \leq y_{n}$ for all $n$.

(iii) if a nondecreasing sequence $\left\{x_{n}\right\} \rightarrow x$, then $x_{n} \leq x$ for all $n \geq 0$,

(iv) if a nonincreasing sequence $\left\{y_{n}\right\} \rightarrow x$, then $y_{n} \geq x$ for all $n \geq 0$.

If there exist $x^{0}, y^{0} \in X$ such that

$$
g\left(x^{0}\right) \leq\left(x^{0}, y^{0}\right),\left(y^{0}\right) \geq\left(y^{0}, x^{0}\right),
$$

then there exist $x, y \in X$ such that

$$
g(x)=F(x, y), g(y)=F(y, x),
$$

That is, $F$ and $g$ have a coupled coincidence point.

Theorem 2.9. Let $(X, \leq)$ be a complete $S$-metric space. Suppose that there is a function $\phi:[0, \infty) \rightarrow[0, \infty)$ with $\phi(t)<t$ and $\lim _{r \rightarrow t^{+}} \phi(r)<t$ for each $t>0$. Further, assume that $F: X \times X \rightarrow X$ and $g: X \rightarrow X$ are two maps such that $F$ has the mixed $g$-monotone property satisfying the following condition:

(i) $\quad F(X \times X) \subseteq g(X)$,

(ii) $g$ is continuous and monotonically increasing.

(iii) $(g, F)$ is commutating pair.

(iv) $S(F(x, y), F(u, v), F(u, v)) \leq \phi\left[\frac{1}{2}(S(g(x), g(u), g(u)+S(g(\mathrm{y}), g(v), g(\mathrm{v}))]\right.$

for all $x, y, u, v \in X$, with $g(x) \leq g(u)$ and $g(y) \geq g(v)$. Also suppose that either

(a) $\quad F$ is continuous or

(b) $\quad X$ has the following properties:

1. if a nondecreasing sequence $\left\{x_{n}\right\} \rightarrow x$, then

$$
x_{n} \leq x \text {, for all } n \geq 0
$$

2. If a nonincreasing sequence $\left\{x_{n}\right\} \rightarrow x$, then

$$
x_{n} \geq x \text {, for all } n \geq 0 \text {. }
$$

If there exist $x_{0}, y_{0} \in X$ such that

$$
g\left(x_{0}\right) \leq F\left(x_{0}, y_{0}\right) \text { and } g\left(y_{0}\right) \geq F\left(y_{0}, x_{0}\right)
$$

Then $F$ and $g$ have a coupled coincidence point that is there exist $x, y \in X$ such that

$$
g(x)=F(x, y) \quad \text { and } \quad g(y)=F(y, x)
$$

Proof. Let us suppose that $x, y \in X$, we construct the sequences $\left\{x_{n}\right\}$ and $\left\{y_{n}\right\}$ in $X$ such that

$$
g\left(x_{n+1}\right)=F\left(x_{n}, y_{n}\right) \quad \text { and } \quad g\left(y_{n+1}\right)=F\left(y_{n}, x_{n}\right)
$$


Now, we shall show that for $n \geq 0$

$$
g\left(x_{n}\right) \leq g\left(x_{n+1}\right) \quad \text { and } \quad g\left(y_{n}\right) \geq\left(y_{n+1}\right)
$$

So (6) holds for $n=0$. Assume (6) holds for some $n>0$.

Suppose

and

$$
\begin{aligned}
g\left(x_{n+1}\right) & =F\left(x_{n}, y_{n}\right) \\
& \leq F\left(x_{n+1}, y_{n}\right) \\
& \leq F\left(x_{n+1}, y_{n+1}\right) \\
& =g\left(x_{n+2}\right)
\end{aligned}
$$

$$
\begin{aligned}
g\left(y_{n+1}\right) & =F\left(y_{n}, x_{n}\right) \\
& \geq F\left(y_{n+1}, x_{n}\right) \\
& \geq F\left(y_{n+1}, x_{n+1}\right) \\
& =g\left(y_{n+2}\right)
\end{aligned}
$$

Then by induction (6) holds for all $n \geq 0$.

Using (5) and (6), we get

$$
\begin{aligned}
S\left(g\left(x_{m}\right), g\left(x_{m+1}\right), g\left(x_{m+1}\right)\right) & =S\left(F\left(x_{m-1}, y_{m-1}\right), F\left(x_{m}, y_{m}\right), F\left(x_{m}, y_{m}\right)\right) \\
& \leq \phi\left[\frac { 1 } { 2 } \left(S\left(g\left(x_{m-1}\right), g\left(x_{m}\right), g\left(x_{m}\right)+S\left(g\left(y_{m-1}\right), g\left(y_{m}\right), g\left(y_{m}\right)\right)\right]\right.\right.
\end{aligned}
$$

Similarly, we can write by induction

$$
S\left(g\left(y_{m}\right), g\left(y_{m+1}\right), g\left(y_{m+1}\right)\right) \leq \phi\left[\frac { 1 } { 2 } \left(S\left(g\left(x_{m-1}\right), g\left(x_{m}\right), g\left(x_{m}\right)+S\left(g\left(y_{m-1}\right), g\left(y_{m}\right), g\left(y_{m}\right)\right)\right]\right.\right.
$$

So, by putting

We get

$$
\delta_{m}=S\left(g\left(x_{m}\right), g\left(x_{m+1}\right), g\left(x_{m+1}\right)+S\left(g\left(y_{m}\right), g\left(y_{m+1}\right), g\left(y_{m+1}\right)\right)\right.
$$

$$
\begin{aligned}
\delta_{m} & =S\left(g\left(x_{m}\right), g\left(x_{m+1}\right), g\left(x_{m+1}\right)+S\left(g\left(y_{m}\right), g\left(y_{m+1}\right), g\left(y_{m+1}\right)\right)\right. \\
& \leq \phi\left[\frac { 1 } { 2 } \left(S\left(g\left(x_{m-1}\right), g\left(x_{m}\right), g\left(x_{m}\right)+S\left(g\left(y_{m-1}\right), g\left(y_{m}\right), g\left(y_{m}\right)\right)\right]\right.\right. \\
& =2 \phi\left(\frac{1}{2} \delta_{m-1}\right)
\end{aligned}
$$

Since $\phi(t)<t$ for $t>0$. So, $\delta_{m} \leq \delta_{m-1}$ for all $m$ so that $\left\{\delta_{m}\right\}$ is a nonincreasing sequence, since it is bounded below sequence, there exist some $\delta>0$ such that

$$
\lim _{m \rightarrow \infty} \delta_{m}=+\delta \text {. }
$$

We have prove that $\delta=0$. On the other hand suppose that $\delta>0$. Putting limit as $m \rightarrow+\infty$ on both sides of (7) and having $\lim _{r \rightarrow t^{+}} \phi(r)<t$ for all $t>0$ in mind, we have,

$$
\begin{aligned}
\delta & =\lim _{m \rightarrow \infty} \delta_{m} \leq \lim _{m \rightarrow \infty} 2 \phi\left(\frac{1}{2} \delta_{m-1}\right) \\
& =2 \phi\left(\frac{1}{2} \delta\right)<2 \cdot \frac{\delta}{2}=\delta
\end{aligned}
$$

Which gives us a contradiction so $\delta=0$.

Therefore,

$$
\lim _{m \rightarrow \infty} S\left(g\left(x_{m}\right), g\left(x_{m+1}\right), g\left(x_{m+1}\right)+S\left(g\left(y_{m}\right), g\left(y_{m+1}\right), g\left(y_{m+1}\right)\right)=0\right.
$$

Now, we will show that the sequences $\left\{g\left(x_{m}\right)\right\}$ and $\left\{g\left(y_{m}\right)\right\}$ are Cauchy sequence. If possible, assume that atleast one of $\left\{g\left(x_{m}\right)\right\}$ and $\left\{g\left(y_{m}\right)\right\}$ is not a Cauchy sequence. Then there exist $\varepsilon>0$ and sequence of positive integers $\{1(K)\}$ and $\{m(K)\}$ such that for all positive integers $K$,

$$
m(K)>1(K)>K \text {. }
$$


Now,

$$
S\left(g\left(x_{1(K)}\right), g\left(x_{m(K)-1}\right), g\left(x_{m(K)-1}\right)\right)+S\left(g\left(y_{1(K)}\right), g\left(y_{m(K)-1}\right), g\left(y_{m(K)-1}\right)\right) \geq \varepsilon .
$$

$$
\begin{aligned}
\varepsilon \leq & S\left(g\left(x_{1(K)}\right), g\left(x_{m(K)}\right), g\left(x_{m(K)}\right)\right)+S\left(g\left(y_{1(K)}\right), g\left(y_{m(K)}\right), g\left(y_{m(K)}\right)\right) \\
\leq & S\left(g\left(x_{1(K)}\right), g\left(x_{m(K)-1}\right), g\left(x_{m(K)-1}\right)\right)+S\left(g\left(y_{1(K)}\right), g\left(y_{m(K)-1}\right), g\left(y_{m(K)-1}\right)\right) \\
& +S\left(g\left(x_{m(K)-1}\right), g\left(x_{m(K)}\right), g\left(x_{m(K)}\right)\right)+S\left(g\left(y_{m(K)-1}\right), g\left(y_{m(K)}\right), g\left(y_{m(K)}\right)\right)
\end{aligned}
$$

That is

$$
\begin{aligned}
\varepsilon & \leq S\left(g\left(x_{1(K)}\right), g\left(x_{m(K)}\right), g\left(x_{m(K)}\right)\right)+S\left(g\left(y_{1(K)}\right), g\left(y_{m(K)}\right), g\left(y_{m(K)}\right)\right) \\
& \leq \varepsilon+S\left(g\left(x_{m(K)-1}\right), g\left(x_{m(K)}\right), g\left(x_{m(K)}\right)\right)+S\left(g\left(y_{m(K)-1}\right), g\left(y_{m(K)}\right), g\left(y_{m(K)}\right)\right)
\end{aligned}
$$

Taking $k \rightarrow \infty$ in the above inequality and using $(8)$, we get

$$
\lim _{k \rightarrow \infty}\left[S\left(g\left(x_{1(K)}\right), g\left(x_{m(K)}\right), g\left(x_{m(K)}\right)+S\left(g\left(y_{1(K)}\right), g\left(y_{m(K)}\right), g\left(y_{m(K)}\right)\right)\right]=\varepsilon\right.
$$

Again, we have

$$
\begin{aligned}
& S\left(g\left(x_{1(K)+1}\right), g\left(x_{m(K)+1}\right), g\left(x_{m(K)+1}\right)\right)+S\left(g\left(y_{1(K)+1}\right), g\left(y_{m(K)+1}\right), g\left(y_{m(K)+1}\right)\right) \\
& \leq S\left(g\left(x_{1(K)+1}\right), g\left(x_{1(K)}\right), g\left(x_{1(K)}\right)\right)+S\left(g\left(y_{1(K)+1}\right), g\left(y_{1(K)}\right), g\left(y_{1(K)}\right)\right) \\
&+S\left(g\left(x_{1(K)}\right), g\left(x_{m(K)}\right), g\left(x_{m(K)}\right)\right)+S\left(g\left(y_{1(K)}\right), g\left(y_{1(K)}\right), g\left(y_{1(K)}\right)\right) \\
&+S\left(g\left(x_{m(K)}\right), g\left(x_{m(K)+1}\right), g\left(x_{m(K)+1}\right)\right)+S\left(g\left(y_{m(K)}\right), g\left(y_{m(K)+1}\right), g\left(y_{m(K)+1}\right)\right) \\
& S\left(g\left(x_{1(K)}\right)\right.\left., g\left(x_{m(K)}\right), g\left(x_{m(K)}\right)\right)+S\left(g\left(y_{1(K)}\right), g\left(y_{m(K)}\right), g\left(y_{m(K)}\right)\right) \\
& \leq S\left(g\left(x_{1(K)+1}\right), g\left(x_{1(K)}\right), g\left(x_{1(K)}\right)\right)+S\left(g\left(y_{1(K)+1}\right), g\left(y_{1(K)}\right), g\left(y_{1(K)}\right)\right) \\
&+S\left(g\left(x_{1(K)+1}\right), g\left(x_{m(K)+1}\right), g\left(x_{m(K)+1}\right)\right)+S\left(g\left(y_{1(K)+1}\right), g\left(y_{1(K)+1}\right), g\left(y_{1(K)+1}\right)\right) \\
&+S\left(g\left(x_{m(K)}\right), g\left(x_{m(K)+1}\right), g\left(x_{m(K)+1}\right)\right)+S\left(g\left(y_{m(K)}\right), g\left(y_{m(K)+1}\right), g\left(y_{m(K)+1}\right)\right)
\end{aligned}
$$

Taking $K \rightarrow \infty$ in above inequalities and using (8) and (9), we obtain,

$$
\lim _{k \rightarrow \infty}\left[S\left(g\left(x_{1(K)+1}\right), g\left(x_{m(K)+1}\right), g\left(x_{m(K)+1}\right)+S\left(g\left(y_{1(K)+1}\right), g\left(y_{m(K)+1}\right), g\left(y_{m(K)+1}\right)\right)\right]=\varepsilon\right.
$$

Now,

$$
\begin{aligned}
& S\left(g\left(x_{1(K)+1}\right), g\left(x_{m(K)+1}\right), g\left(x_{m(K)+1}\right)\right)+S\left(g\left(y_{1(K)+1}\right), g\left(y_{m(K)+1}\right), g\left(y_{m(K)+1}\right)\right) \\
& \leq S\left(F\left(x_{1(K)}, y_{1(K)}\right), F\left(x_{m(K)}, y_{m(K)}\right), F\left(x_{m(K)}, y_{m(K)}\right)\right) \\
&+S\left(F\left(y_{1(K)}, x_{1(K)}\right), F\left(y_{m(K)}, x_{m(K)}\right), F\left(x_{m(K)}, y_{m(K)}\right)\right) \\
& \leq \phi\left[\frac { 1 } { 2 } \left(S\left(g\left(x_{1(K)}\right), g\left(x_{m(K)}\right), g\left(x_{m(K)}\right)+S\left(g\left(y_{1(K)}\right), g\left(y_{m(K)}\right), g\left(y_{m(K)}\right)\right)\right] .\right.\right.
\end{aligned}
$$

Assuming $K \rightarrow \infty$ in the above inequality and using (9) and (10) and the property of $\phi$, we get

$$
\varepsilon \leq 2 \phi\left(\frac{\varepsilon}{2}\right)<2 \cdot \frac{\varepsilon}{2}=\varepsilon
$$

Which leads to a contradiction. Therefore $\left\{g\left(x_{m}\right)\right\}$ and $\left\{g\left(y_{m}\right)\right\}$ are Cauchy sequences in $(X, S)$. Since the metric space $(X, S)$ is complete, therefore there exist $x, y \in X$ such that

$$
\lim _{m \rightarrow \infty} g\left(x_{m}\right)=x \text { and } \lim _{m \rightarrow \infty} g\left(y_{m}\right)=y .
$$

Now, $g$ is continuation. So, by the continuity of $g$ and (11), we can get

$$
\lim _{m \rightarrow \infty} g\left(g\left(x_{m}\right)\right)=g(x) \quad \text { and } \quad \lim _{m \rightarrow \infty} g\left(g\left(y_{m}\right)\right)=g(y) .
$$

Using (5) and the commutativity of $F$ and $g$, we have

and

$$
\begin{aligned}
g\left(g\left(x_{m+1}\right)\right) & =g\left(F\left(x_{m}, y_{m}\right)\right) \\
& =F\left(g\left(x_{m}\right), g\left(y_{m}\right)\right)
\end{aligned}
$$

$$
\begin{aligned}
g\left(g\left(y_{m+1}\right)\right) & =g\left(F\left(y_{m}, x_{m}\right)\right) \\
& =F\left(g\left(y_{m}\right), g\left(x_{m}\right)\right)
\end{aligned}
$$

Now, we will show that $F$ and $g$ have a coupled coincidence point. To, prove this, suppose (a) holds, then by (5) and (12) and the continuous of $F$ and $g$, we get 


$$
\begin{aligned}
g(x) & =\lim _{m \rightarrow \infty} g\left(g\left(x_{m+1}\right)\right) \\
& =\lim _{m \rightarrow \infty} g\left(F\left(x_{m}, y_{m}\right)\right) \\
& =F\left(\lim _{m \rightarrow \infty} g\left(x_{m}\right), \lim _{m \rightarrow \infty} g\left(y_{m}\right)\right) \\
& =F(x, y)
\end{aligned}
$$

Similarly, we can show that

$$
g(y)=F(y, x) .
$$

Hence, the element $(x, y) \in X \times X$ is a coupled coincidence point of the mappings $F$ and $g$. Now, suppose that (6) holds. Since $\left\{g\left(x_{m}\right)\right\}$ and $\left\{g\left(y_{m}\right)\right\}$ is nondecreasing and nonincreasing respectively, and

$$
\begin{aligned}
& g\left(x_{m}\right) \rightarrow x \text { as } m \rightarrow \infty, \\
& g\left(y_{m}\right) \rightarrow y \text { as } m \rightarrow \infty,
\end{aligned}
$$

we have

$$
g\left(x_{m}\right) \leq x \text { and } g\left(y_{m}\right) \geq y .
$$

Since $g$ is monotonically increasing. So,

$$
g\left(g\left(x_{m}\right)\right) \leq g(x) \text { and } g\left(g\left(y_{m}\right)\right) \geq g(y) .
$$

Using triangle inequality together with (5), we have

$$
\begin{aligned}
S(g(x), F(x, y), F(x, y)) \leq & S\left(g\left(g\left(x_{m+1}\right)\right), F(x, y), F(x, y)\right)+S\left(g\left(g\left(x_{m+1}\right)\right), g(x), g(x)\right) \\
\leq & S\left(g\left(g\left(x_{m+1}\right)\right), g(x), g(x)\right) \\
& +\phi\left[\frac { 1 } { 2 } \left(S \left(g\left(g\left(x_{m+1}\right), g(x), g(x)\right)+\left(S\left(g\left(g\left(y_{m+1}\right), g(y), g(y)\right)\right]\right.\right.\right.\right.
\end{aligned}
$$

Letting $m \rightarrow \infty$ in this inequality and using (12), we get $g(x)=F(x, y)$. Similarly, we can show that $g(y)=F(y, x)$.

Which shows that $F$ and $g$ have a coupled coincidence point.

Corollary 2.10. Let $(X, S)$ is a complete $S$-metric space. Suppose that three is a function $\phi:[0, \infty) \rightarrow[0, \infty)$ with $\phi(t)<t$ and $\lim _{r \rightarrow t^{+}} \phi(r)<t$ for each $t>0$. Further, assume that $F: X \times X \rightarrow X$ is a mapping such that $F$ has the mixed monotone property satisfying the following conditions:

$$
S(F(x, y), F(u, v), F(u, v)) \leq \phi\left[\frac{1}{2}(S(x, u, u), g(\mathrm{y}, \mathrm{v}, \mathrm{v})]\right.
$$

for all $x, y, u, v \in X$ with $x \leq u$ and $y \geq v$.

Also, suppose that either

(a) $\quad F$ is continuous or

(b) $\quad X$ has the following properties:

$$
\begin{aligned}
& \text { If a nondecreasing sequence }\left\{x_{n}\right\} \rightarrow x \text {, then } \\
& x_{n} \leq x \text { for all } n \geq 0
\end{aligned}
$$

If a nonincreasing sequence $\left\{x_{n}\right\} \rightarrow x$, then

$$
x_{n} \geq x \text { for all } n \geq 0
$$

If there exist $x_{0}, y_{0} \in X$ such that

$$
x_{0} \leq F\left(x_{0}, y_{0}\right) \text { and } y_{0} \leq F\left(y_{0}, x_{0}\right)
$$

Then $F$ has a coupled fixed point in $X$, that is there exist $x, y \in X$ such that

$$
x=F(x, y) \text { and } y=F(y, x)
$$

Proof. Assuming $g=I$, the identity mapping, in Theorem 2.9, we get the above Corollary 2.10.

Corollary 2.11. Let $(X, S)$ be a complete S-metric space. Suppose that $F: X \times X \rightarrow X$ and $g: X \rightarrow X$ are two maps such that $F$ has the mixed $g$-monotone property satisfying the following conditions:

(i) $\quad F(X \times X) \subseteq g(X)$

(ii) $g$ is continuous and monotonically increasing, 
(iii) $(g, F)$ is a commutating pair,

(iv) $\quad S(F(x, y), F(u, v), F(u, v)) \leq \frac{k}{r}[S(g(x), g(u), g(u))+S(g(y), g(v), g(v))], k \in[0,1)$

for all $x, y, u, v \in X$ with $g(x) \leq g(u)$ and $g(y) \geq g(v)$. Also, assume that either

(a) $\quad F$ is continuous or

(b) $X$ has the following properties:

(i) If a nondecreasing sequence $\left\{x_{n}\right\} \rightarrow x$, then $x_{n} \leq x$ for all $n \geq 0$

(ii) If a nonincreasing sequence $\left\{x_{n}\right\} \rightarrow x$, then $x_{n} \geq x$ for all $n \geq 0$

If there exist $x_{0}, y_{0} \in X$ such that

$$
g\left(x_{0}\right) \leq F\left(x_{0}, y_{0}\right) \text { and } g\left(y_{0}\right) \leq F\left(y_{0}, x_{0}\right)
$$

Then $F$ and $g$ have a coupled fixed point in $X$, i.e. there exist $x, y \in X$ such that $g(x)=F(x, y)$ and $\quad g(y)=F(y, x)$

Proof. Taking $\phi(t)=k \cdot t$ with $k \in[0,1)$ in Theorem 2.9, we obtain the above Corollary 2.11

\section{References}

[1] B.C. Dhage, Generalized metric space and mapping with fixed point, Bull. Cal. Math. Soc. 84, 1992, 329-336.

[2] S. Gahlers, 2-metrische Raume and ihre topologische structure, Math.Nachr, 26, 1963, 115-148.

[3] S. Gahlers, Zur geometric 2-metrische raume, Revue Roumaine Math. Pures Appl., 11, 1966, 665-667.

[4] Z. Mustafa and B. Sims, A new approach to generalized metric spaces, Journal of Nonlinear and Convex Analysis, 7 (2), 2006, 289297.

[5] S. Sedghi, N. Shobe and A. Aliouche, A generalization of fixed point theorems in S-metric spaces, Mat. Vesnik, 64 (3) (2012), 258266.

[6] S. Sedghi and N.V. Dzung, Fixed point theorems on S-metric spaces, accepted for publication in Mat. Vesnik (2012).

[7] T.V. An and N.V. Dung, Two fixed point theorems in S-metric spaces, preprint (2012).

[8] Z. Mustafa and B. Sims, Fixed point theorems for contractive mappings in complete G-metric spaces, Fixed Point Theory Appl. 2009, 10 (2009). Article ID 917175

[9] T.G. Bhaskar and V. Lakshmikantham, Fixed point theory in partially ordered metric spaces and applications, Nonlinear Anal., 65 (2006), 1379-1393.

[10] D.W. Boyd and S.W. Wong, On nonlinear contractions, Proc. Am. Math. Soc., 20, 1969, 458-464, doi:10.1090/S0002-9939-19690239559-9.

[11] M. Imdad et al, On n-tupled coincidence point results in metric spaces, Journal of Operators, 2013, 8 pages.

[12] Z. Mustafa, H. Obiedat and F. Awawdeh, Some fixed point theorem for mapping on complete metric spaces, Fixed Point Theory Appl., 2008, 12 (2008). Article ID 189870.

[13] V. Lakshmikantham and L. Ciric, Coupled fixed point theorems for nonlinear contractions in partially ordered metric spaces, Nonlinear Analysis: Theory, Methods \& Applications A, 70 (12), 2009, 4341-4349.

[14] T. Gnana Bhaskar and V. Lakshmikantham, Fixed point theorems in partially ordered metric spaces and applications, Nonlinear Analysis: Theory, Methods \& Applications A, 65 (7), 2006, 1379-1393. 